\title{
Morfo-anatomia de plântulas e número cromossômico de Cybistax antisyphilitica (Mart.) Mart. (Bignoniaceae) ${ }^{1}$
}

\author{
Flavia Aparecida Ortolani ${ }^{2,4}$, Márcia Fiorese Mataqueiro², José Roberto Moro², Fabíola Vitti Moro³ e \\ Carlos Ferreira Damião Filho ${ }^{3}$
}

Recebido em 8/01/2007. Aceito em 13/06/2007

\begin{abstract}
RESUMO - (Morfo-anatomia de plântulas e número cromossômico de Cybistax antisyphilitica (Mart.) Mart. (Bignoniaceae)). Plântulas de Cybistax antisyphilitica (ipê-verde), espécie arbórea que ocorre no Estado de São Paulo, Brasil, foram estudadas morfoanatomicamente e citogeneticamente. As plântulas são eudicotiledôneas, fanerocotiledonares e epigéias. Suas sementes apresentam alas hialinas, assimétricas e de textura papirácea. A raiz é axial com tecido epidérmico irregular. O hipocótilo é verde, glabro e apresenta os elementos do xilema em diferenciação. Os cotilédones são verdes, foliáceos, reniformes, com mesofilo heterogêneo, epiderme pilosa e feixes vasculares colaterais. Os eófilos são glabros, peciolados, de filotaxia oposta, dorsiventrais, hipoestomáticos e possuem mesofilo heterogêneo e assimétrico. Não há diferenças anatômicas significativas entre os eófilos e os metáfilos. O sistema vascular do pecíolo dos metáfilos dispõe-se em forma de ferradura. A espécie apresenta número cromossômico mitótico $2 \mathrm{n}=40 \mathrm{com}$ comprimento cromossômico geral médio de $1,042 \mu \mathrm{m} \pm 0,140$ e amplitude variando de $0,58 \mu \mathrm{m}$ até $1,60 \mu \mathrm{m}$.
\end{abstract}

Palavras-chave: morfologia, anatomia, número cromossômico, Bignoniaceae, plântula

\begin{abstract}
Seedling morpho-anatomy and chromosome number of Cybistax antisyphilitica (Mart.) Mart. (Bignoniaceae)). Seedlings of Cybistax antisyphilitica ("ipê-verde"), a tree species found in the state of São Paulo, Brazil, were studied as regards morphology, anatomy and cytogenetics. The seedlings are eudicotyledonous, phanerocotylar, epigeous and the seeds have hyaline, asymmetric, paper-textured expansions. The root system is axial with irregular epidermal tissue. The hypocotyl is green, glabrous and has differentiated xylem elements. The cotyledons are green, foliaceous, kidney-shaped, with heterogeneous mesophyll, pilose epidermis and collateral vascular bundles. The eophylls are petiolate, glabrous, with opposite phyllotaxy, dorsiventral, hypostomatic and with heterogeneous, asymmetric mesophyll. There are no significant anatomical differences between eophylls and metaphylls. The metaphyll petiole vascular system is shaped like a horseshoe. The species has a mitotic chromosome number $2 \mathrm{n}=40$ with average overall chromosome length of $1.042 \mu \mathrm{m} \pm 0.140$ and width varying from $0.58 \mu \mathrm{m}$ to $1.60 \mu \mathrm{m}$.
\end{abstract}

Key words: morphology, anatomy, chromosome number, Bignoniaceae, seedling

\section{Introdução}

A família Bignoniaceae compreende, aproximadamente, 113 gêneros e 800 espécies. O Brasil é considerado o centro da diversidade de Bignoniáceas, pois, no país, ocorrem 60 gêneros e cerca de 338 espécies, distribuídas desde os cerrados até as florestas úmidas, incluindo os táxons endêmicos (Gentry 1980). Dentro desta família destaca-se a espécie Cybistax antisyphilitica (Mart.) Mart., popularmente conhecida como ipê-verde ou ipê-caroba. Por ser considerada uma planta pioneira e ter preferência a solos arenosos e pedregosos, essa árvore, de porte pequeno, é visada em programas de reflorestamento destinados à recomposição da vegetação, além de ser utilizada na arborização de ruas e parques. Sua madeira tem pouca importância na construção civil, pois é pouco resistente ao apodrecimento, por este motivo é empregada na fabricação de ripas, caixas e pasta celulósica (Lorenzi 1992).

A fase inicial do desenvolvimento de uma planta é, muitas vezes, definida como um período crítico para o ciclo de vida de diversas espécies vegetais, sendo que uma falha adaptativa no estágio de plântula pode levar à extinção da espécie (Souza \& Oliveira 2004), pois é nesta fase que os indivíduos mostram-se

\footnotetext{
Parte da Tese de Doutorado do primeiro Autor

2 Universidade Estadual Paulista, Departamento de Biologia Aplicada à Agropecuária, Laboratório de Citogenética, Via de Acesso Prof. Paulo Donato Castellane s.n., 14884-900 Jaboticabal, SP, Brasil

3 Universidade Estadual Paulista, Departamento de Biologia Aplicada à Agropecuária, Laboratório de Morfologia Vegetal, Via de Acesso Prof. Paulo Donato Castellane s.n., 14884-900 Jaboticabal, SP, Brasil

4 Autor para correspondência: fortol@ig.com.br
} 
adaptados ou não à determinado tipo de ambiente (Moraes \& Paoli 1999). A associação de estudos de anatomia e morfologia permite a compreensão de todo o processo fisiológico, estrutural e ecológico das plantas florestais (Mourão et al. 2002). Além dos estudos morfo-anatômicos, a citogenética pode atuar como instrumento auxiliar na identificação taxonômica, nos casos nos quais as características fenotípicas não são totalmente confiáveis para determinar a classificação das plantas e, em muitos casos, permite esclarecer os fundamentos citológicos e genéticos da variabilidade (Martinez 1976 apud Silveira et al. 2006).

Estudos morfológicos, anatômicos e citogenéticos, em espécies arbóreas, têm atraído a atenção de alguns pesquisadores (Souza \& Moscheta 1992; Piazzano 1998; Moraes \& Paoli 1999; Oliveira 2001; Alcorcés de Guerra 2002; Mourão et al. 2002; Souza \& Oliveira, 2004; Correia et al. 2005; Oliveira et al. 2006). No entanto, o número de trabalhos encontrados na literatura brasileira ainda é pequeno, tendo em vista a situação crítica de desmatamento no nosso território. $\mathrm{Na}$ natureza, os impactos ambientais causados pelo homem vêm se intensificando a cada ano exigindo imediata conservação de plantas remanescentes e a rápida recuperação das áreas degradadas. Para a produção de mudas de uma determinada espécie vegetal, entretanto, é necessário o conhecimento sobre floração, frutificação, germinação e morfologia das plantas (Correia et al. 2005). Essas informações favorecem a identificação das plantas em um determinado ambiente natural, além de beneficiar pesquisas agronômicas e taxonômicas (Parra 1984; Correia et al. 2005).

O presente trabalho visa descrever e analisar a morfo-anatomia de plântulas e a citogenética da espécie Cybistax antisyphilitica (Mart.) Mart., com o objetivo de levantar informações que possam auxiliar na identificação e na preservação da espécie, bem como na recomposição de áreas degradadas.

\section{Material e métodos}

Sementes de $C$. antisyphilitica foram coletadas no campus da UNESP/FCAV, Jaboticabal (SP), Brasil. Esses exemplares foram postos para germinar, em laboratório, em placas de Petri, forradas com papel filtro umedecido com nistatina $2 \%$, à temperatura ambiente. As sementes germinadas, caracterizadas pela protrusão da raiz primária, permaneceram neste meio durante 15 dias. Após este período foram transferidas para sacos plásticos, contendo uma mistura de terra, areia e substrato agrícola Plantmax, em partes iguais.
As fases de crescimento morfológico das plântulas foram esquematizadas e caracterizadas aos zero, 5, 15, 22 e 50 dias de idade. Todas essas fases foram documentadas por esquemas realizados com o auxílio de um estereomicroscópio equipado com câmara clara. A análise morfológica foi baseada na descrição de Rizzini (1977) e Damião Filho (2005). Para estudar-se o tipo de germinação, sementes da espécie foram semeadas em caixas de gerbox contendo areia úmida previamente esterilizada à $120^{\circ} \mathrm{C}$ por três horas.

Para o estudo anatômico foram confeccionadas lâminas histológicas com cortes transversais e/ou longitudinais da raiz, hipocótilo, cotilédone, eófilo, metáfilo e pecíolo, de acordo com os métodos descritos por Johansen (1940). A coloração foi feita utilizandose safranina $2 \%$ por 25 minutos. A documentação das epidermes superior e inferior foi efetuada por desenhos elaborados ao microscópio fotônico com câmara clara, projetando-se nas mesmas condições as escalas correspondentes. A análise anatômica foi baseada em Fahn (1974) e Appezzato-da-Glória \& CarmelloGuerreiro (2004).

O número cromossômico diplóide foi determinado usando-se ápices de raízes com cerca de 2,0 cm de comprimento que foram coletadas e tratadas com 8 hidroxiquinoleína $0,003 \mathrm{M}$ por três horas à $36^{\circ} \mathrm{C}$. Em seguida, foram fixadas em solução Carnoy (3 metanol : 1 ácido acético glacial) e mantidas em geladeira por 48 horas. As raízes passaram por três lavagens seguidas, em água destilada, com duração de cinco minutos cada. Posteriormente, foram hidrolisadas em $\mathrm{HCl} 1 \mathrm{~N}$ à $60^{\circ} \mathrm{C}$, por doze minutos e os tecidos meristemáticos foram macerados sobre lâminas com ácido acético 45\%. Após secagem as lâminas foram coradas em solução Giemsa $2 \%$ por quatro minutos. A observação do material foi realizada em microscópio ZEISS com aumento de até 1000x. Para a contagem dos cromossomos foram analisadas 10 metáfases e esse procedimento foi auxiliado pelo sistema de imagem IKAROS (Metasystems). A biometria cromossômica foi efetuada com o programa KS-300, versão 2.02 da Kontron Elektronik, utilizando-se também 10 metáfases. Os comprimentos cromossômicos médios e seus respectivos desvios-padrão foram obtidos com a utilização do programa Excel (Microsoft).

\section{Resultados e discussão}

Morfologia - Cybistax antisyphilitica é uma angiosperma, eudicotiledônea, fanerocotiledonar e 
epigéia. Suas sementes, de formato cordiforme, são aladas, estenospérmicas e com hilo evidente. A testa apresenta coloração em tom castanho com expansões aladas, hialinas, assimétricas e de textura papirácea (Fig. 1a). Segundo Barroso et al. (1999) sementes de Bignoniáceaes não possuem endosperma e o embrião é cotiledonar, contínuo, transverso-oblongo e com eixo hipocótilo-radícula reto. Todos esses dados corroboram os encontrados na espécie em estudo. A assimetria das alas é uma característica favorável na dispersão anemocórica, pois proporciona maior distância percorrida pela semente (Oliveira et al. 2006). Algumas espécies de Bignoniaceae como Tabebuia chrysotricha (Mart. ex Dc.) Standl., Tabebuia ochraceae (Chamisso) Standley e Anemopaegma chamberlaynii Bur. \& K. Schum. apresentam, na germinação, o caráter de poliembrionia (Piazzano 1998; Costa et al. 2004b; Correia et al. 2005). No entanto, essa característica não foi observada na espécie C. antisyphilitica.

O processo de germinação (Fig. 1b) teve início 24 horas após o rompimento do tegumento pela radícula, que ocorreu por volta do quarto dia. O sistema radicular mostra-se axial e ramificado (Fig. 1c, 1d e 1e). O coleto é visível por apresentar diferença de coloração entre o hipocótilo clorofilado e a raiz aclorofilada. Tanto o hipocótilo quanto o epicótilo são de coloração verde e completamente desprovidos de tricomas. Os cotilédones são peciolados, bilobados, foliáceos, reniformes, clorofilados e com recortes apicais profundos (Fig. 1c e 1e). As plântulas apresentam dois eófilos simétricos, glabros, peciolados e de filotaxia oposta. Possuem ápice obtuso, base cuneada e margem levemente serreada. Até o $50^{\circ}$ dia de crescimento não foi possível observar externamente a venação do eófilo, notando-se apenas a disposição de um feixe vascular central (Fig. 1e). É importante salientar que as folhas adultas do ipê-verde são, morfologicamente, diferentes dos eófilos, pois possuem ápice falcado, isto é, a porção terminal da folha é comprida, estreita e desviada para um dos lados.

A plântula estudada pode ser incluída no tipo Macaranga (Vogel 1980) por mostrar-se fanerocotiledonar, com cotilédones finos, persistentes, verdes e de função assimiladora após a germinação, com maior desenvolvimento do hipocótilo e eófilos de filotaxia oposta. Também se enquadra no tipo fanero-epígeofoliáceo descrito por Miquel (1987).

Alguns estudos indicam a predominância da germinação epígea para Bignoniáceas (Ferreira \& Cunha 2000; Souza \& Oliveira 2004). Quando os cotilédones estão acima do solo, geralmente, são fotossintéticos (Mayer \& Poljakoff-Mayber 1963). Segundo Cabral et al. (2004) os cotilédones são importantes fontes de energia e responsáveis pelo crescimento inicial da planta e sua remoção pode causar redução da biomassa na planta jovem.

As características morfológicas descritas para C. antisyphilitica corrobora muitos dos dados relatados por Ferreira \& Cunha (2000) para a Bignoniácea Tabebuia caraiba (Mart.) Bur., exceto que, diferentemente do ipê-verde, os eófilos possuem ápice agudo, base obtusa e tricomas em sua superfície.

Anatomia - Os cotilédones da espécie analisada possuem epiderme unisseriada, cuticularizada, com tricomas glandulares pluricelulares de formatos variados, tanto na face adaxial como na abaxial (Fig. 2a, $2 \mathrm{c}$ e $2 \mathrm{~d}$ ). Os estômatos são encontrados somente na face abaxial (Fig. 2b). O mesófilo é clorofilado,

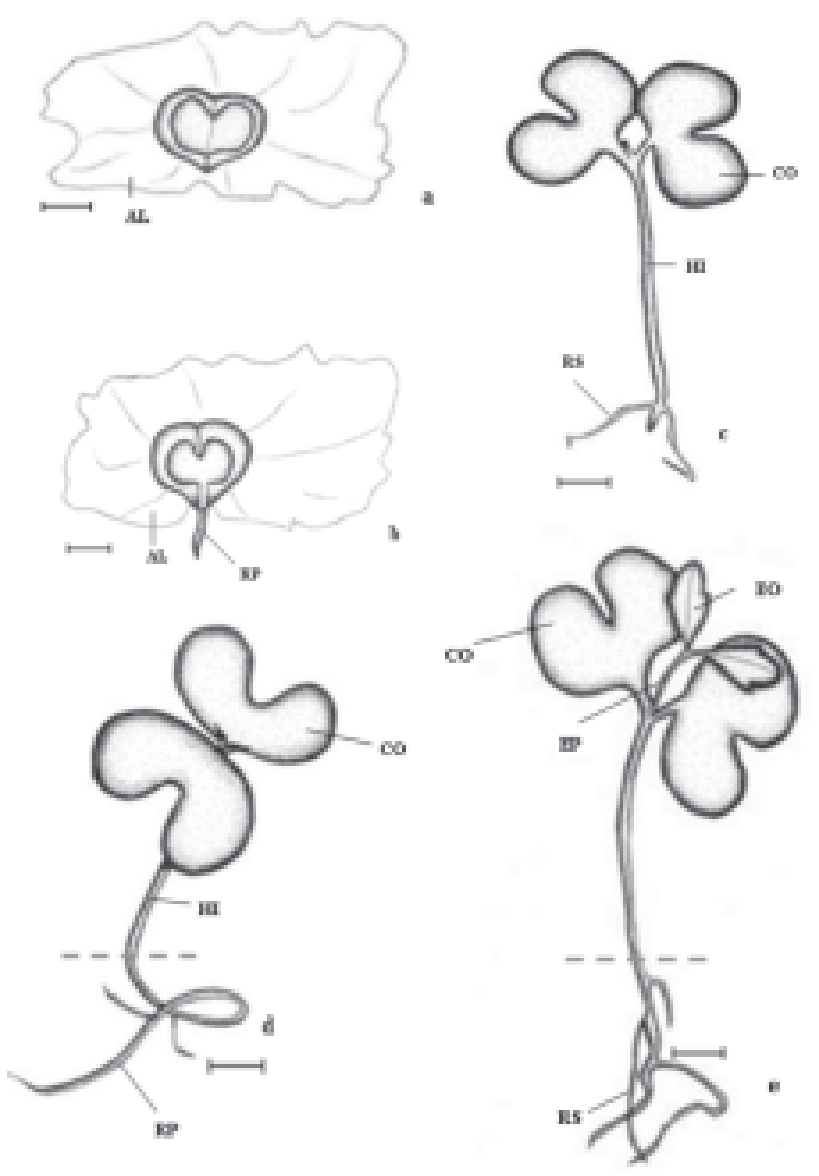

Figura 1. Aspecto externo da semente e plântulas de Cybistax antisyphilitica em crescimento aos: a - 0 dias; $\mathrm{b}$ - 5 dias; $\mathrm{c}-15$ dias; d - 22 dias; e -50 dias de idade. $(\mathrm{AL}=$ ala; $\mathrm{CO}=$ cotilédone; $\mathrm{EO}=$ eófilo; $\mathrm{EP}=$ epicótilo; $\mathrm{HI}=$ hipocótilo; $\mathrm{RP}=$ raiz primária; $\mathrm{RS}=$ raiz secundária). Barras $=5 \mathrm{~mm}$. O tracejado evidencia a região do coleto. 
parenquimático e heterogêneo, sendo constituído de uma camada de parênquima paliçádico voltada para a epiderme da face adaxial e várias camadas de parênquima lacunoso voltadas para a epiderme da face abaxial (Fig. 2a e 2c). A vascularização é feita por feixes colaterais (Fig. 2b). Essas características são semelhantes àquelas relatadas para Tabebuia chrysotricha (Mart. ex Dc.) Standl. Entretanto, Tabebuia avellanedae Lor. ex Griseb apresenta características cotiledonares bem diferentes, pois possuem mesofilo homogêneo e tricomas isolados na epiderme da face adaxial (Souza \& Oliveira 2004).

Os eófilos são dorsiventrais, hipoestomáticos; possuem epiderme cuticularizada, unisseriada com tricomas glandulares. O mesofilo é heterogêneo e assimétrico com apenas uma camada de parênquima paliçádico voltada para a epiderme da face adaxial e duas a quatro camadas de parênquima lacunoso voltadas para a epiderme da face abaxial (Fig. 3a), ambos diferenciados em tecidos fotossintetizantes. Estruturalmente, a nervura central dos metáfilos (Fig. 4a) não apresenta diferenças significativas quando comparada à dos eófilos (Fig. 3b), exceto por um maior diâmetro dos vasos condutores nos metáfilos. Esses dados coincidem com os encontrados no gênero Tabebuia (Bignoniaceae) por Souza \& Oliveira (2004). Geralmente, as folhas de Bignoniáceas são dorsiventrais, sendo registrada estrutura isobilateral apenas no gênero Kigelia (Metcalfe \& Chalk 1957). Segundo Fahn (1974), de modo geral, o mesofilo sofre diferenciação para dar lugar aos tecidos fotossintetizantes e, por isso, está repleto de cloroplastos. A Fig. 4b mostra o padrão helicoidal de deposição da parede secundária sobre a parede primária nos elementos de vaso e elementos do tubo crivado com placas crivadas levemente inclinadas. No padrão helicoidal há poucas regiões com deposição de parede secundária e, por isso, pode facilmente sofrer um colapso. No entanto, esse padrão tem a vantagem de extensibilidade e essa característica permite que os elementos de vaso se diferenciem em tecidos que estão crescendo, já que podem se alongar e continuar funcionais, levando água até as partes jovens da planta (Costa et al. 2004a). Nos metáfilos os estômatos estão localizados somente na epiderme da face abaxial e são anomocíticos (Fig. 5). Esse tipo estomático também
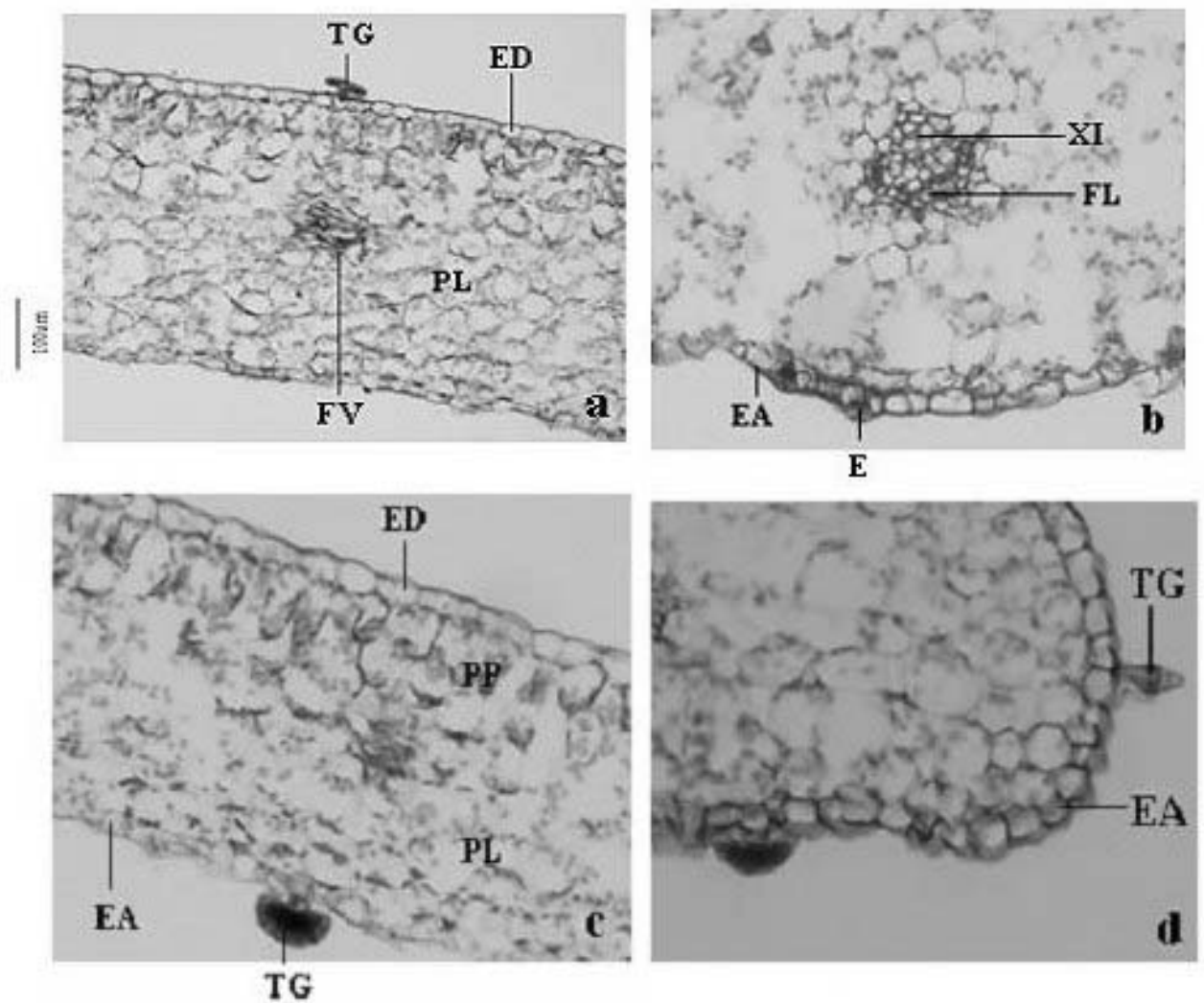

Figura 2. Secções transversais da folha cotiledonar, evidenciando: $\mathrm{E}=$ estômato; $\mathrm{EA}=$ epiderme abaxial, $\mathrm{ED}=$ epiderme adaxial; $\mathrm{FL}$ = floema; $\mathrm{FV}=$ feixe vascular; $\mathrm{PL}=$ parênquima lacunoso; $\mathrm{PP}=$ parênquima paliçádico; $\mathrm{TG}=$ tricoma glandular; $\mathrm{XI}=\mathrm{xilema}$. 
foi relatado por Souza \& Oliveira (2004) para as espécies Tabebuia chrysotricha (ipê-amarelocascudo) e Tabebuia avellanedae (ipê-roxo) e este aparato pode ser utilizado como um caráter em taxonomia vegetal (Fahn 1974).

A epiderme do pecíolo dos metáfilos é unisseriada e apresenta tricomas glandulares na epiderme da face abaxial (Fig. 6a). O córtex e a medula são
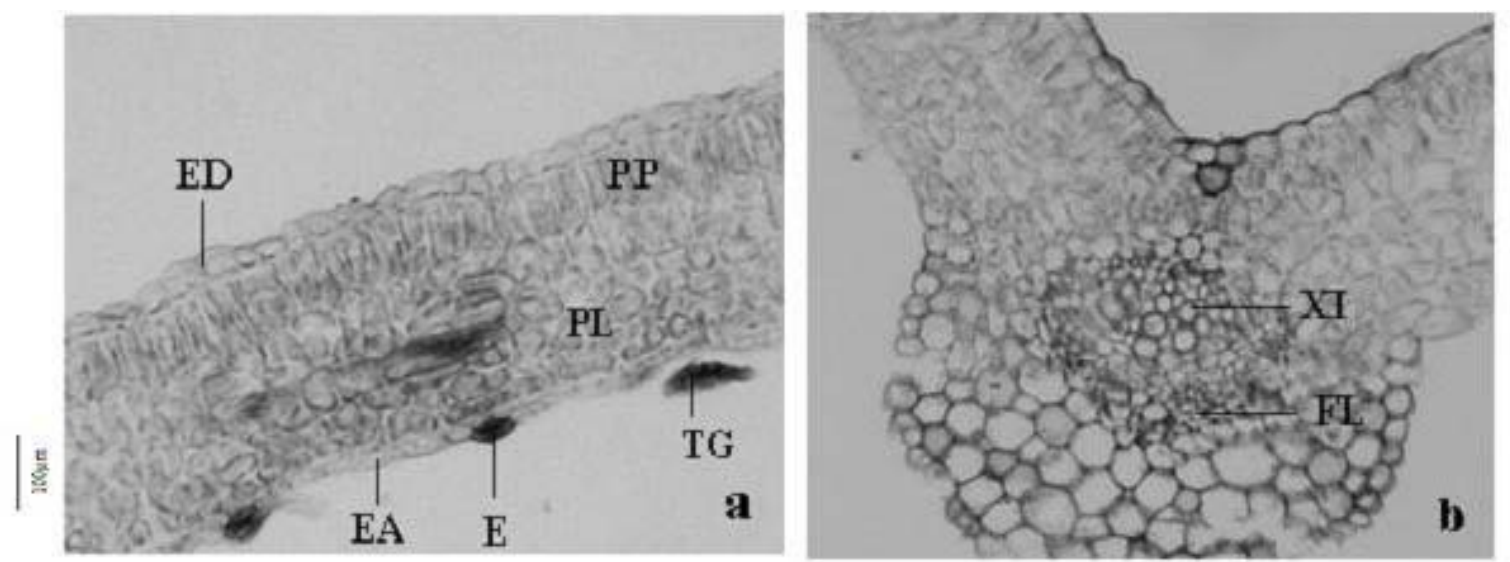

Figura 3. Secções transversais do eófilo. a. Lâmina foliar. b. Nervura central. $(E=$ estômato; $E A=$ epiderme abaxial; $E D=$ epiderme adaxial; FL = floema; $\mathrm{PL}=$ parênquima lacunoso; $\mathrm{PP}=$ parênquima paliçádico; $\mathrm{TG}$ = tricoma glandular; $\mathrm{XI}=$ xilema).
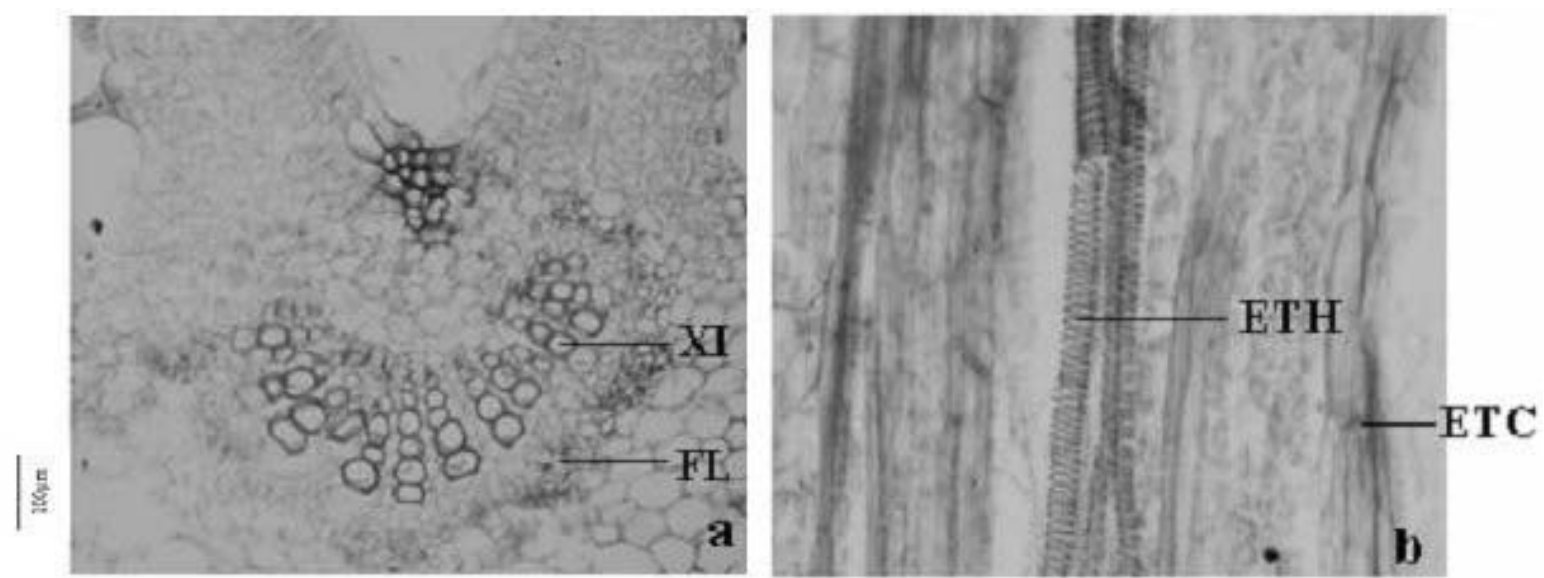

Figura 4. Secção transversal e longitudinal do metáfilo, respectivamente. a. Nervura central. b. Elementos de vaso. $($ ETH $=$ elemento traqueal helicoidal; ETC = elemento de tubo crivado; FL = floema; $\mathrm{XI}=$ xilema).
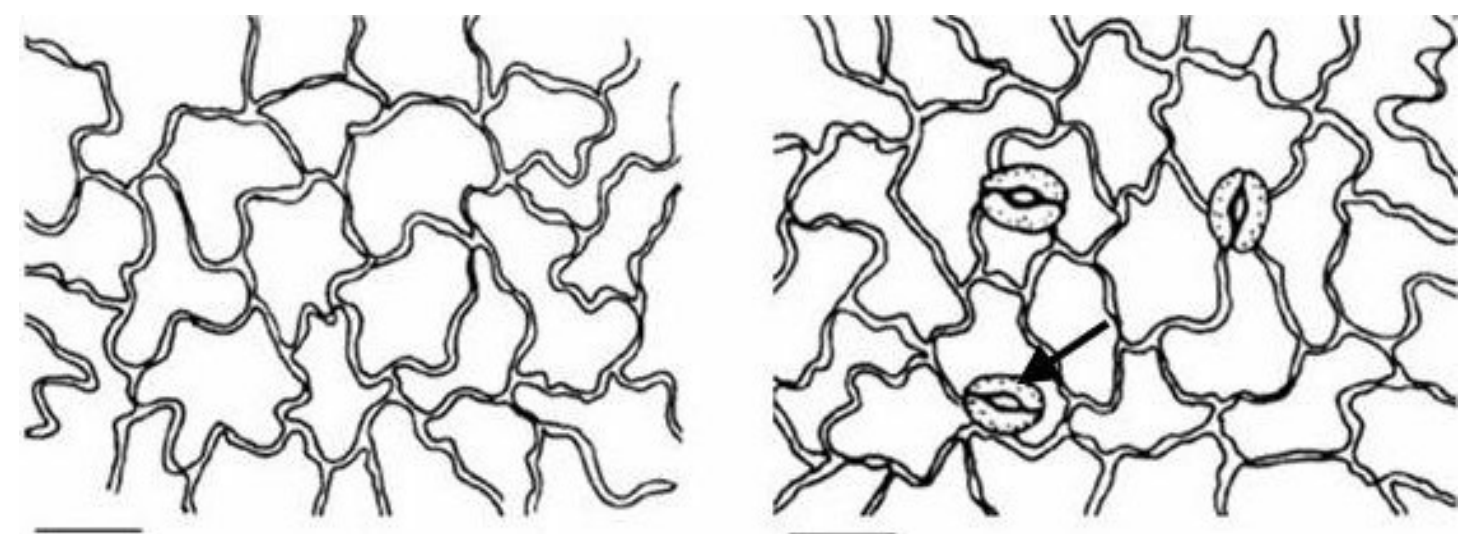

Figura 5. Epiderme das faces abaxial e adaxial do metáfilo em vista frontal, respectivamente. Seta indica estômato anomocítico. Barras $=50 \mu \mathrm{m}$. 
parenquimáticos e, estruturalmente, é semelhante ao hipocótilo quanto ao córtex, medula e tricomas. $\mathrm{O}$ sistema vascular está organizado sob forma de ferradura (Fig. 6b).

O hipocótilo apresenta epiderme unisseriada, irregular e contém tricomas glandulares uni e pluricelulares, além de tectores uni e pluricelulares de extremidade afilada. Possui elementos de vaso em diferenciação, caracterizados pela formação de metaxilema externamente ao protoxilema (Fig. 7a e $7 b)$ e, neste caso, o protoxilema é endarco. Segundo Sajo \& Castro (2004) o caule, geralmente, desenvolve-se a partir do epicótilo, embora haja espécies onde a parte superior do eixo hipocótiloradícula possa constituí-lo. Em leguminosas, o hipocótilo não é considerado como um órgão composto de raiz e caule, mas sim como uma região especializada e indiferenciada (Compton 1912 apud Souza \& Oliveira 2004), não apresentando, portanto, elementos em diferenciação. Em Tabebuia avellanedae e Tabebuia chrysotricha o hipocótilo representa a região de conexão entre o caule e a raiz (Souza \& Oliveira 2004), por conseguinte, o cilindro central apresenta estrutura de transição, caracterizado pela divisão radial do metaxilema e afastamento lateral de suas células.

O tecido epidérmico da raiz é unisseriado, irregular e possui uma fina camada de cutícula. Os tricomas absorventes estão restritos à base radicular não ocorrendo em regiões próximas ao ápice. O córtex é constituído de várias camadas de células parenquimáticas que podem apresentar grãos de amido. $\mathrm{O}$ cilindro vascular é sólido e provido de seis arcos de xilema sendo, portanto, a raiz hexarca e protostélica. Diferentemente do hipocótilo, a diferenciação dos elementos do xilema é exarca, isto é, diferencia-se centripetamente da periferia do cilindro vascular em direção ao centro. Sendo assim, os elementos protoxilema estão voltados para a periferia do órgão
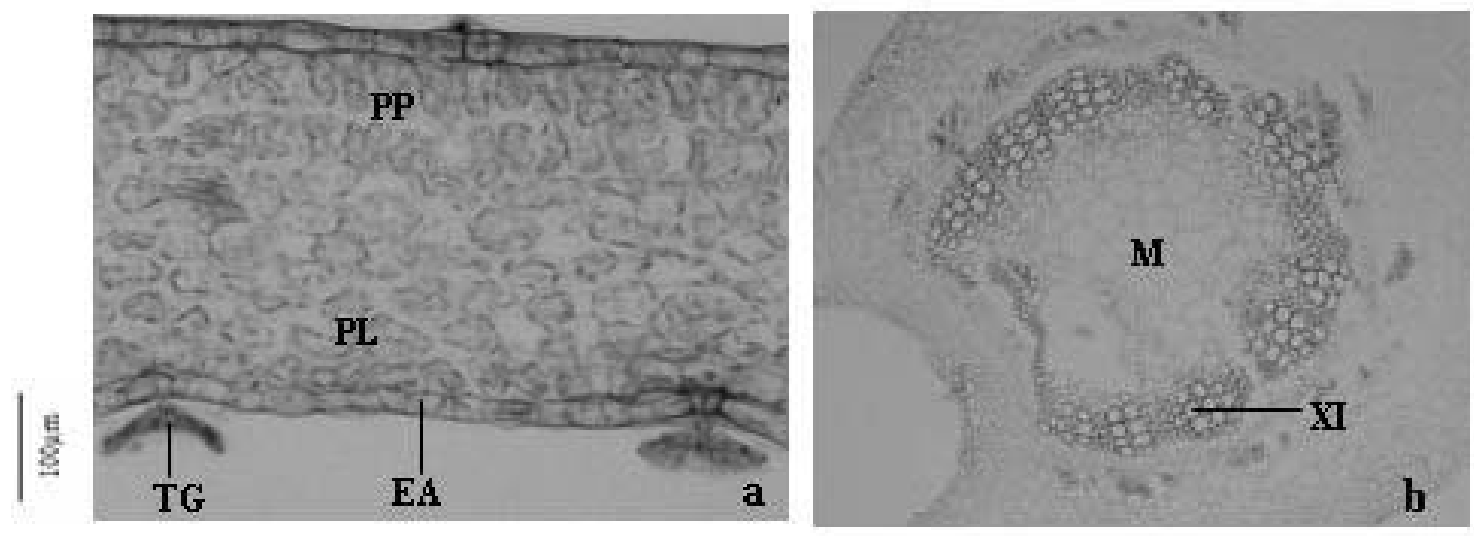

Figura 6. Secção longitudinal e transversal do pecíolo, respectivamente (EA = epiderme abaxial; $\mathrm{M}=$ medula; $\mathrm{PL}=$ parênquima lacunoso; $\mathrm{PP}=$ parênquima paliçádico; $\mathrm{TG}=$ tricoma glandular; $\mathrm{XI}=$ xilema).
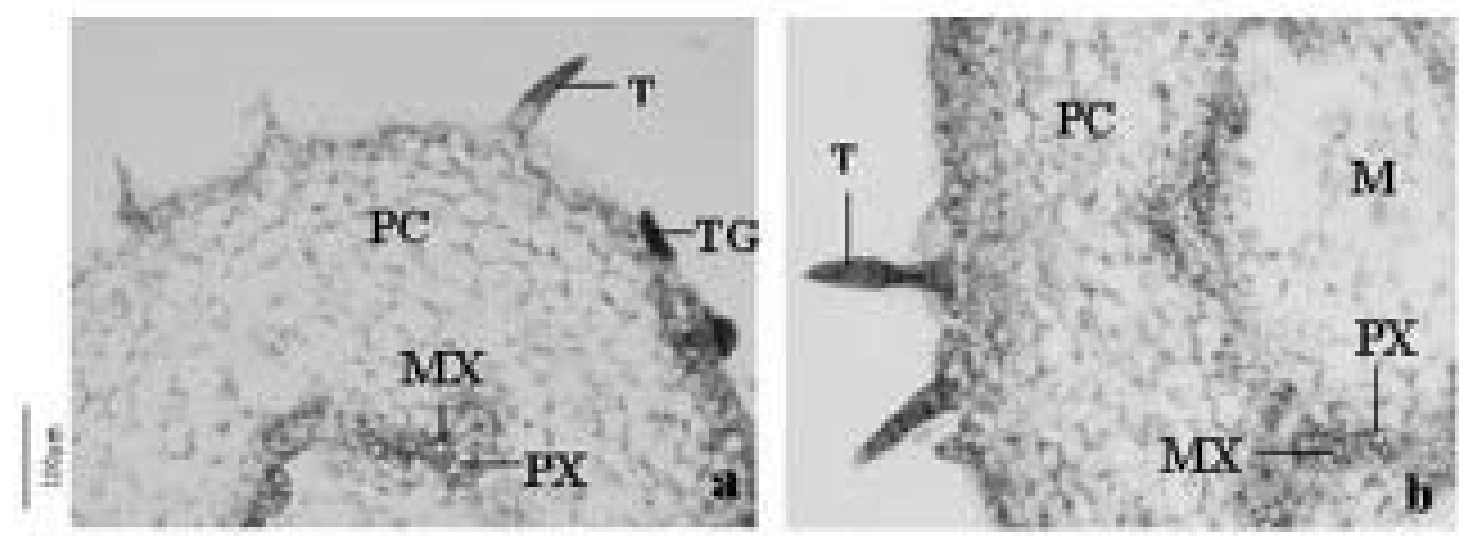

Figura 7. Secções transversais do hipocótilo $(\mathrm{M}=$ medula; $\mathrm{MX}=$ metaxilema; $\mathrm{PC}=$ parênquima cortical; $\mathrm{PX}=$ protoxilema; $\mathrm{T}=$ tector; $\mathrm{TG}=$ tricoma glandular; $\mathrm{XI}=$ xilema) . 
e os elementos de metaxilema para o interior (Fig. 8a). Em regiões próximas ao hipocótilo a raiz desta espécie pode apresentar uma medula parenquimática (Fig. 8b). De acordo com Sajo \& Castro (2004) a posição do protoxilema é uma das características mais importantes para diferenciar raiz e caule, principalmente quando estes já se encontram em estrutura secundária. Souza \& Oliveira (2004) relataram que raízes de Tabebuia chrysotricha também são hexarcas e pode apresentar medula esclerificada nas proximidades do hipocótilo.

Os aspectos morfoanatômicos da plântula estudada apresentaram-se bem homogêneos, sendo, portanto, confiáveis na identificação de mudas em viveiros ou em matas. Além do interesse teóricocientífico, esses dados também são importantes nos estudos sobre regeneração de ecossistemas naturais e de preservação da espécie em questão. Grande parte das espécies nativas de Bignoniáceas, entretanto, carece de informações morfológicas e anatômicas, o que indica a necessidade de mais estudos que utilizem espécies de Bignoniaceae de modo a estabelecer um amplo conhecimento sobre esta família e a flora brasileira.

Citogenética - As metáfases analisadas apresentaram número cromossômico diplóide $2 \mathrm{n}=40$ cromossomos (Fig. 9) com comprimento médio cromossômico total de 1,042 $\mu \mathrm{m} \pm 0,140$ (Tab. 1) e amplitude variando de $0,58 \mu \mathrm{m}$ até $1,60 \mu \mathrm{m}$. Os cromossomos desta espécie são pequenos e uniformes, o que dificulta a classificação dos mesmos quanto à posição do centrômero, tornando difícil o reconhecimento de um par cromossômico em particular. Dentro das Bignoniáceas, o número cromossômico predominante é $2 \mathrm{n}=40$ cromossomos (Piazzano 1998; Alcorcés de
Guerra 2002). Espécies do gênero Jacaranda (Bignoniaceae) apresentam 2n= 36 cromossomos (Piazzano 1998) o que mostra que esta família é citogeneticamente heterogênea. Geralmente, as Bignoniáceas apresentam euploidias $(2 \mathrm{n}=40$, 60 e 80 cromossomos) o que indica que o número básico haplóide para esta família é de $\mathrm{n}=\mathrm{x}=20$ (Goldblatt 1976). Segundo Piazzano (1998) as espécies Tabebuia heptaphylla (Vell.) Toledo, Tabebuia impetiginosa (Dc.) Standley e Tabebuia pulcherrima Sandwith possuem $2 \mathrm{n}=40$ cromossomos. Alcorcés de Guerra (2002) relatou que Tabebuia chrysanta (Jacq.) Nichols e Tabebuia capitata (Bur. \& Schum.) Sandw. também apresentam $2 \mathrm{n}=40$ cromossomos, com comprimento cromossômico médio variando de $0,984 \mu \mathrm{m} \pm 0,085$ à $1,882 \mu \mathrm{m} \pm 0,082$, respectivamente A uniformidade cromossômica também foi relatada para as espécies Macfadyena ungüis-cati (L) A. Gentry, Macfadyena dentata K. Schum. e Arrabidaea selloi (Spreng.) Sandwith, todas pertencentes à família Bignoniaceae (Piazzano 1998). Características como número cromossômico diplóide elevado, cromossomos pequenos, comprimentos cromossômicos basicamente constantes dentro do mesmo cariótipo e poliploidia são consistentes com o padrão esperado para plantas lenhosas tropicais (Goldblatt 1976; Piazzano 1998; Biondo et al. 2005).

Devido ao pequeno tamanho dos cromossomos e a não visualização do centrômero, os dados citogenéticos aqui relatados não podem atuar como ferramenta de auxílio na identificação da espécie em questão. No entanto, fornecem subsídios para futuros estudos que envolvam a manipulação cromossômica e possível produção de híbridos para fins econômicos.
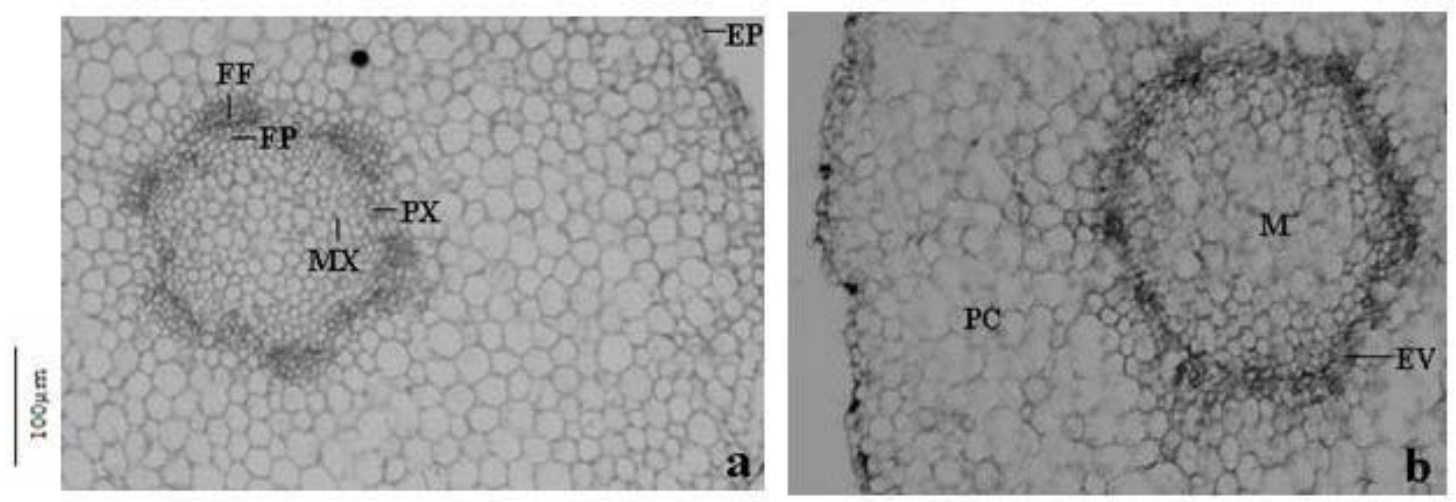

Figura 8. Secções transversais da raiz $(\mathrm{EP}=$ epiderme; $\mathrm{EV}=$ elementos de vaso; $\mathrm{FF}=$ fibras de floema; $\mathrm{FP}=$ floema primário; $\mathrm{M}=$ medula; $\mathrm{MX}=$ metaxilema $; \mathrm{PC}=$ parênquima cortical $; \mathrm{PX}=$ protoxilema). 


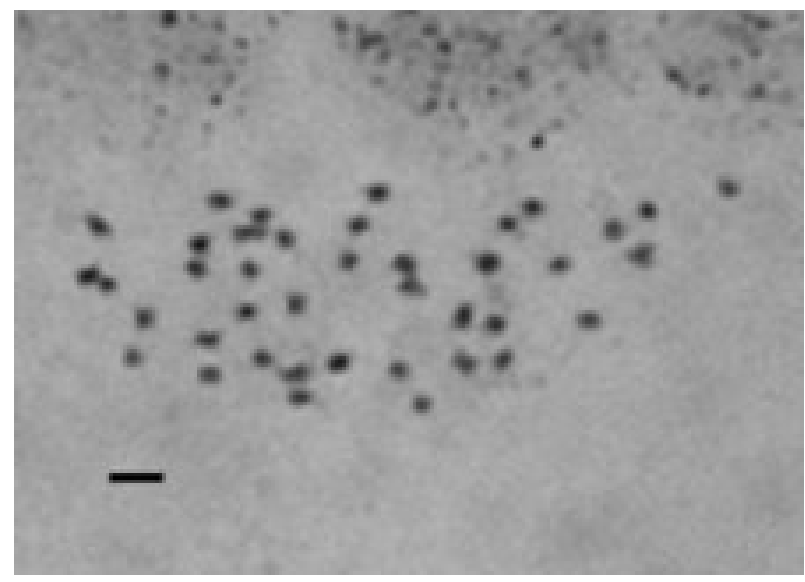

Figura 9. Metáfase mitótica de C. antisyphilitica, mostrando $2 \mathrm{n}=40$ cromossomos. Barra $=3,0 \mu \mathrm{m}$.

Tabela 1. Valores do comprimento médio total dos cromossomos de Cybistax antisyphilitica (Mart.) Mart. (ipê-verde). * $\mathrm{CM}=$ comprimento médio dos cromossomos $(\mu \mathrm{m}) ; \sigma=$ desvio padrão.

\begin{tabular}{crrccc}
\hline $\begin{array}{c}\text { Par } \\
\text { cromossômico }\end{array}$ & $* \mathrm{CM}$ & $\sigma$ & $\begin{array}{c}\text { Par } \\
\text { cromossômico }\end{array}$ & $* \mathrm{CM}$ & $\sigma$ \\
\hline \multirow{2}{*}{1} & 1,458 & 0,137 & 11 & 1,017 & 0,125 \\
& 1,431 & 0,144 & & 1,011 & 0,132 \\
2 & 1,364 & 0,138 & 12 & 1,011 & 0,132 \\
& 1,313 & 0,142 & & 0,999 & 0,135 \\
3 & 1,268 & 0,148 & 13 & 0,982 & 0,141 \\
& 1,257 & 0,122 & & 0,967 & 0,140 \\
4 & 1,236 & 0,133 & 14 & 0,949 & 0,145 \\
& 1,208 & 0,144 & & 0,940 & 0,143 \\
5 & 1,185 & 0,144 & 15 & 0,939 & 0,143 \\
& 1,170 & 0,140 & & 0,929 & 0,116 \\
6 & 1,142 & 0,150 & 16 & 0,919 & 0,123 \\
& 1,116 & 0,137 & & 0,905 & 0,140 \\
7 & 1,095 & 0,129 & 17 & 0,868 & 0,139 \\
& 1,090 & 0,130 & & 0,853 & 0,145 \\
8 & 1,080 & 0,135 & 18 & 0,837 & 0,143 \\
& 1,080 & 0,135 & & 0,823 & 0,150 \\
9 & 1,050 & 0,143 & 19 & 0,804 & 0,169 \\
& 1,048 & 0,145 & & 0,781 & 0,149 \\
10 & 1,039 & 0,150 & 20 & 0,748 & 0,144 \\
& 1,038 & 0,149 & & 0,725 & 0,148 \\
Tamanho médio dos cromossomos $(\mu \mathrm{m})$ & 1,042 & \\
Desvio padrão médio & & & & 0,140 \\
\hline
\end{tabular}

\section{Referências bibliográficas}

Alcorcés de Guerra, N. 2002. Cariologia de dos espécies del gênero Tabebuia Gomes (Bignoniaceae). Revista Científica UDO Agrícola 2: 14-21.

Appezzatto-da-Glória, B. \& Carmello-Guerreiro, S.M. 2004. Anatomia vegetal. Viçosa, Editora da Universidade Federal de Viçosa
Barroso, G.M.; Morim, M.P.; Peixoto, A.L. \& Ichaso, C.L.F. 1999. Frutos e Sementes. Morfologia aplicada à sistemática de dicotiledôneas. Viçosa, Editora da Universidade Federal de Viçosa

Biondo, E.; Miotto, S.T.S.; Schifino-Wittmann, M.T. 2005. Citogenética de espécies arbóreas da subfamília Caesalpinioideae - Leguminosae do sul do Brasil. Ciência Florestal 15: 241-248.

Cabral, E.L.; Barbosa, D.C.A. \& Simabukuro, E.A. 2004. Crescimento de plantas jovens de Tabebuia aurea (Manso) Benth. \& Hook. f. ex. S. Moore submetidas a estresse hídrico. Acta Botanica Brasilica 18: 241-251.

Correia, M.C.R.; Pinheiro, M.C.B. \& Lima, H.A. 2005. Produção de frutos e germinação de sementes de Anemopaegma chamberlaynii Bur. \& K. Schum. (Bignoniaceae) - Um registro de poliembrionia, Sitientibus Série Ciências Biológicas 5: 68-71.

Costa, C.G.; Callado, C.H.; Coradin, V.T.R. \& CarmelloGuerreiro, S.M. 2004a. Xilema. Pp. 129-141. In: B. Appezzato-da-Glória \& S.M. Carmello-Guerreiro. Anatomia Vegetal. Rio de Janeiro, Brasília e Campinas, Editora UFV.

Costa, M. E.; Sampaio, D.S.; Paoli, A.A.S. \& Leite, S.C.A.L. 2004b. Poliembrionia e aspectos da embriogênese em Tabebuia ochracea (Chamisso) Standley (Bignoniaceae). Revista Brasileira de Botânica 27: 395-406.

Damião Filho, C.F. 2005. Morfologia Vegetal. Jaboticabal, Editora Funep.

Fahn, A. 1974. Anatomia vegetal. Madrid, H. Blume Ediciones Ed.

Ferreira, R.A. \& Cunha, M.C.L. 2000. Aspectos morfológicos de sementes, plântulas e desenvolvimento da muda de craibeira (Tabebuia caraiba (Mart.) Bur.) - Bignoniaceae e pereiro (Aspidosperma pyrifolium Mart.) Apocynaceae. Revista Brasileira de Sementes 22: 134-143.

Gentry, A.H. 1980. Bignoniaceae. Part I (Tribes Crescentiae and Tourrettieae). Flora Neotropica, Monograph 25: $1-130$.

Goldblatt, P. 1976. New or noteworthy chromosome records in the angiosperms. Annual Missouri Botanic Garden 64: 889-895.

Johansen, D.A. 1940. Plant microtechnique. New York and London, McGraw-Hill Book Company Ed.

Lorenzi, H. 1992. Árvores brasileiras: manual de identificação e cultivo de plantas arbóreas nativas do Brasil. v.I. Nova Odessa, Editora Instituto Plantarium.

Mayer, A.M. \& Poljakoff-Mayber, A. 1963. The germination of seedlings. New York, The MacMillan Company Ed.

Metcalfe, C.R. \& Chalk, L. 1957. Anatomy of the dicotyledons - leaves, stem and wood in relation to taxonomy with notes on economic uses. v. II. Oxford, Claredon Press Ed.

Miquel, S. 1987. Morphologie, fonctionnelle de plantules d'éspèces forestières du Gabon. Bulletin du Muséum Nacional D'Histoire Naturelle 1: 102-120. 
Moraes, P.L.R. \& Paoli, A.A.S. 1999. Morfologia e estabelecimento de plântulas de Cryptocarya moschata Nees, Ocotea catharinensis Mez e Endlicheria paniculata (Spreng.) MacBride - Lauraceae. Revista Brasileira de Botânica 22: 287-295.

Mourão, K.S.M.; Dias-Pinto, D.; Souza, L.A. \& Moscheta, S.M. 2002. Morfo-anatomia da plântula e do tirodentro de Trichilia catigua A. Juss., T. elegans A. Juss. e T. pallida Sw, (Meliaceae). Acta Scientiarum 24: 601-610.

Oliveira, A.K.M.; Scheider, E.D. \& Favero, S. 2006. Caracterização morfológica, viabilidade e vigor de sementes de Tabebuia aurea (Silva Manso) Benth. \& Hook. f. ex. S. Moore. Revista Árvore 30: 25-32.

Oliveira, D.M.T. 2001. Morfologia comparada de plântulas e plantas jovens de leguminosas arbóreas nativas: espécies de Phaseoleae, Sophoreae, Swartzieae e Tephrosieae. Revista Brasileira de Botânica 24: 85-97.

Parra, P.G. 1984. Estúdio de la morfologia externa de plântulas de Calliandra gracilis, Mimosa albida, Mimosa arenosa, Mimosa camporum y Mimosa tenuiflora. Revista de la Facultad de Agronomia 13: 311-350.
Piazzano, M. 1998. Números cromosómicos en Bignoniaceae de Argentina. Kurtziana 26: 179-189.

Rizzini, C.T. 1977. Sistematização terminológica da folha. Rodriguésia 29: 103-125.

Sajo, M.G. \& Castro, N.M.C. 2004. Caule. Pp. 283-302. In: B. Appezzato-da-Glória \& S.M. Carmello-Guerreiro. Anatomia Vegetal. Rio Claro e Uberlândia, Editora da Universidade Federal de Viçosa

Silveira, F.T.; Ortolani, F.A.; Mataqueiro, M.F. \& Moro, J.R. 2006. Caracterização citogenética em duas espécies do gênero Myrciaria. Revista de Biologia e Ciências da Terra 6: 327-333.

Souza, L.A. \& Moscheta, I.S. 1992. Morfo-anatomia do fruto e da plântula de Aspidosperma polyneuron M. Arg. (Apocynaceae). Revista Brasileira de Biologia 52: 439-447.

Souza, L.A. \& Oliveira, J.H.G. 2004. Morfologia e anatomia das plântulas de Tabebuia avellaneade Lor. ex Griseb e T. chrysotricha (Mart. ex Dc.) Standl. (Bignoniaceae). Acta Scientiarum 26: 217-226.

Vogel, E.F. 1980. Seedlings of dicotyledons - structure, development, types. Pudoc, Wagening Ed. 